\title{
A novel model based on interleukin 6 and insulin-like growth factor II for detection of hepatocellular carcinoma associated with hepatitis $C$ virus
}

Mohamed M. Omran ${ }^{1 *}$ D, Sara Mosaad ${ }^{2}$, Tarek M. Emran ${ }^{3}$, Fathy M. Eltaweel ${ }^{2}$ and Khaled Farid ${ }^{4}$

\begin{abstract}
Background: The coexistence of cirrhosis complicates the early detection of hepatocellular carcinoma (HCC). Thus, novel biomarkers for HCC early detection are needed urgently. Traditionally, HCC detection is carried out by evaluating alpha-fetoprotein (AFP) levels combined with imaging techniques. This work aimed to assess interleukin (IL-6) and insulin-like growth factor 2 (IGF 2) as possible HCC markers in comparison to AFP in patients with and without HCC.

Results: ROC analysis showed that IGF2 had the highest area under the curve (AUC) for discriminating HCC from liver cirrhosis (0.86), followed by IL6 (0.82), AFP (0.72), and platelet count (0.6). A four-marker model was developed and discriminated HCC from liver cirrhosis with an AUC of 0.97. The best cut-off was 1.28, at which sensitivity and specificity were $90 \%$ and $85 \%$, respectively. For small tumor $(<2 \mathrm{~cm})$, the model had an AUC of 0.95 compared to AFP (0.72). Also, the model achieved perfect performance with AUC of 0.93, 0.94, and 0.95 for BCLC (0-A), CLIP (0-1), and Okuda (stage I), respectively, compared to AFP (AUC of 0.71, 0.69, and 0.67 , respectively).
\end{abstract}

Conclusions: The four markers may serve as a diagnostic model for HCC early stages and help overcome AFP poor sensitivity.

Keywords: Hepatocellular carcinoma, Diagnosis, Blood markers, Interleukin, Insulin-like growth factor 2

\section{Impact statement}

Worldwide, hepatocellular carcinoma is the sixth most common cancer and the second leading cause of death. The current work aimed to evaluate interleukin and insulin-like growth factor 2 as possible HCC markers compared to alpha-fetoprotein (AFP).

\footnotetext{
* Correspondence: drmmomran@science.helwan.edu.eg; drmmomran@yahoo.com

${ }^{1}$ Chemistry Department, Faculty of Science, Helwan University, Ain Helwan, Cairo 11795, Egypt

Full list of author information is available at the end of the article
}

\section{Background}

Worldwide, HCC is the commonest aggressive liver cancer $[1,2]$. It is the 4th common cancer in Egypt, and $\mathrm{HCV}$ is the most risk factor for cirrhosis and HCC development [3]. In many cancers, survival is significantly improved by early detection [4]. AFP is the most used biomarker for detecting $\mathrm{HCC}$ and the only biomarker that has been validated for clinical use but with limited sensitivity. However, AFP has higher sensitivity when used in combination with abdominal ultrasound $(63 \%$ vs. 45\% US alone) [5]. HCC behavior is heterogeneous, with carcinogenesis involving several genetic alterations, and this could explain the limited performance of a single biomarker. A model that includes multiple biomarkers

\section{Springer Open}

() The Author(s). 2021 Open Access This article is licensed under a Creative Commons Attribution 4.0 International License, which permits use, sharing, adaptation, distribution and reproduction in any medium or format, as long as you give appropriate credit to the original author(s) and the source, provide a link to the Creative Commons licence, and indicate if changes were made. The images or other third party material in this article are included in the article's Creative Commons licence, unless indicated otherwise in a credit line to the material. If material is not included in the article's Creative Commons licence and your intended use is not permitted by statutory regulation or exceeds the permitted use, you will need to obtain permission directly from the copyright holder. To view a copy of this licence, visit http://creativecommons.org/licenses/by/4.0/. 
encompassing heterogeneous pathways in carcinogenesis and clinical factors (sex, age, and etiology of liver disease) has been developed and validated to improve the HCC early detection [6]. Carcinogenesis is a complex system that includes stromal cells, endothelial cells, immune cells, cytokines, and growth factors [7]. Thrombocytopenia is used to monitor the development of HCC [8]. IL-6 production during inflammatory conditions and infections is induced via stimulation of cells by IL-1 or tumor necrosis factor (TNF)- $\alpha$ or stimulation of Toll-like receptors after binding of pathogenic patterns of microbes [9]. IL-6 has several roles in HCC including decrease HCC cell apoptosis, stimulate hepatic DNA synthesis, natural killer cell dysfunctions [10, 11]. IGF2 is produced in the liver in response to growth hormone. IGF2 has several roles in the development of liver cirrhosis and HCC through the promotion of hepatocyte proliferation [12]. The current study, aimed to evaluate IL- 6 and IGF 2 as noninvasive HCC biomarkers compared to AFP.

\section{Methods \\ Patients}

Two hundred fifteen chronic hepatitis $C$ patients were recruited between December 2018 and August 2019. Informed consent was signed by all patients in compliance with Helsinki Declaration. The first group included 155 patients with HCC. They were diagnosed according to American Association for the Study of Liver Diseases (AASLD) guidelines, based on AFP $>400$ and the presence of hepatic focal lesion(s) detected by liver ultrasound and confirmed by triphasic computed tomography (CT) and/or dynamic magnetic resonance image (MRI). The second group included 60 patients with HCV-induced liver cirrhosis defined by clinical, biochemical, and imaging findings as splenomegaly. They were followed up for 6 months to ensure the absence of HCC. Patients with HCC were classified using three common staging systems: Barcelona Clinic Liver Cancer (BCLC), Cancer of Liver Italian Program (CLIP), and Okuda systems [13]. None of the patients with HCC previously underwent trans-arterial chemoembolization or radiofrequency ablation. The severity of chronic liver disease was determined using the Child-Pugh score. All patients were positive for $\mathrm{HCV}$-antibody and $\mathrm{HCV}$ RNA. Patients with chronic diseases (cardiovascular, renal, autoimmune, rheumatoid arthritis, or hepatitis B virus) were excluded. In addition, patients with other thrombocytopenia or HCC causes or have other malignancies were also excluded from the study.

\section{Laboratory investigation}

Tri-potassium dihydrogen ethylenediaminetetraacetate was used as an anticoagulant and then platelet count was performed using an automated hematology analyzer
(Micros 60; Horiba medical, Montpellier, France). International normalized ratio (INR) was performed using a special device (Coatron M1; TECO, Neufahrn, Germany). Routine liver function tests were done using serum samples and an automated biochemistry analyzer (BT1500; Biotecnica instruments S.P.A, Italy). Serum AFP and HCV antibodies were evaluated using an immune-fluorescence assay by auto-analyzer (MiniVidas; bioMérieux, Marcy L'Etoile, France). The presence of serum HCV-RNA was determined by quantitative real-time polymerase chain reaction (COBAS Ampliprep/COBAS TaqMan; Roche Diagnostics, Pleasanton). Serum interleukin 6 and insulin-like growth factor II levels $(\mathrm{pg} / \mathrm{ml})$ were ascertained using a quantitative sandwich enzyme immunoassay technique (Elabscience Biotechnology Co., Ltd., USA) according to the manufacturer's instructions. The sensitivity of IL-6 was $7.0 \mathrm{pg} / \mathrm{mL}$, and IGF II was $2.0 \mathrm{Pg} / \mathrm{ml}$. Both intra-CV and inter-CV are $<10 \%$. Laboratory investigators were blind to the clinical data of each examined sample.

\section{Statistical analyses}

SPSS software (SPSS Inc.) version 25.0 was used for data analysis. Categorical data were expressed as numbers or percentages and compared using the Chi-square test or Fisher's exact test, when appropriate. Continuous variables were expressed as means \pm standard deviations (SD) or medians and ranges. The student's $t$ test or the non-parametric Mann-Whitney $U$ test was used for comparing means between two groups. The ANOVA test or the non-parametric Kruskal-Wallis test was used for comparing means between more than two groups. Correlation test investigated the relation between each two variables among each group. ROC analyses were done for markers to differentiate between HCC and cirrhosis, and the best cut-off points and diagnostic indices were calculated. Multivariate linear regression analysis was performed for HCC prediction. All statistical tests were two-sided. $P$ values less than 0.05 were considered significant.

\section{Results}

\section{Clinical and laboratory data of study groups}

More than half of the HCC patients were males (no. = 84; $54 \%)$ compared to more than one-third $(n=26 ; 43.3 \%)$ of liver cirrhosis patients, with no significant difference in age between the two groups. The laboratory and clinical data of the study groups are shown in Table 1. Levels of AST, ALT, AFP, IL6, and IGF2 were significantly higher, but platelet count was significantly lower in HCC compared to other studied groups. There were no significant differences in albumin, bilirubin, and prothrombin-INR. There was no correlation between candidate biomarkers 
Table 1 Clinical and laboratory data of the studied groups

\begin{tabular}{|c|c|c|c|}
\hline Variables & $\begin{array}{l}\text { Cirrhosis group } \\
(n=60)\end{array}$ & $\begin{array}{l}\text { HCC group } \\
(n=155)\end{array}$ & $P$ value \\
\hline Age (year) & $57.1 \pm 8.3$ & $59.4 \pm 7.1$ & 0.1 \\
\hline \multicolumn{4}{|l|}{ Gender } \\
\hline Male no., \% & $26(43 \%)$ & $84(54 \%)$ & \multirow[t]{2}{*}{0.17} \\
\hline Female no., \% & $34(57 \%)$ & $71(46 \%)$ & \\
\hline \multicolumn{4}{|l|}{ Liver function tests } \\
\hline Alanine aminotransferase $(\mathrm{U} / \mathrm{L})$ & $28(22-40)$ & $33(24.5-64)$ & 0.02 \\
\hline Aspartate aminotransferase (U/L) & $31(22-50)$ & $40(28.7-70)$ & 0.049 \\
\hline Total bilirubin (mg/dl) & $0.9(0.7-1.2)$ & $1.2(0.8-1.9)$ & 0.13 \\
\hline Albumin (g/L) & $34.2 \pm 7.1$ & $33.6 \pm 5.0$ & 0.48 \\
\hline Prothrombin-INR & $1.27 \pm 0.2$ & $1.34 \pm 0.4$ & 0.13 \\
\hline \multicolumn{4}{|l|}{ Hematological tests } \\
\hline Platelet count $\left(\times 10^{9} / \mathrm{L}\right)$ & $136(77-171.5)$ & $92.5(61.5-153)$ & 0.03 \\
\hline \multicolumn{4}{|l|}{ HCC tumor marker } \\
\hline a-fetoprotein $(U / L)$ & $11(5.5-18)$ & $65.9(7.8-514)$ & 0.03 \\
\hline Interleukin 6 (pg/ml) & $10.3(7-18.8)$ & $18.9(12.4-45.1)$ & $<0.001$ \\
\hline Insulin-like growth factor II (pg/ml) & $2.6(2-10)$ & $34(11-306.5)$ & 0.001 \\
\hline \multicolumn{4}{|l|}{ Child-Pugh score; $n$ (\%) } \\
\hline Child A & $30(50 \%)$ & $120(77.4 \%)$ & \multirow[t]{2}{*}{$<0.0001$} \\
\hline Child B & $30(50 \%)$ & 35 (22.6\%) & \\
\hline
\end{tabular}

but there was correlation between IL6 and other routine parameters in studied patients (bilirubin $(r=0.52, p<$ $0.0001)$; lymphocytes $(r=59, p=0.005)$; monocytes $(r=$ $0.63, p=0.006)$; basophils $(r=0.86, p<0.0001))$.

\section{The diagnostic performances of the single markers}

The biomarkers diagnostic performance is illustrated in Table 2 according to the AUC. AFP showed an AUC of 0.72 . The best cut-off point was $400 \mathrm{U} / 1$ with $27 \%$ sensitivity and absolute specificity. IGF-2 was the most powerful diagnostic marker with the highest AUC (0.86), followed by IL6 (0.82) and platelet count (0.6). The diagnostic power of single markers in relation with morphological features and staging systems of HCC classification are presented in Tables 3, 4, 5, and 6.

\section{Development of a novel model for HCC diagnosis}

According to the current results, AFP had a poor diagnostic performance, and there was a limited diagnostic value of a single biomarker because of HCC biological heterogeneity. Furthermore, there were no correlations between the biomarkers. All these data imply that each biomarker provides distinct information. It was anticipated that the diagnostic performance would improve if individual potential biomarkers (AFP, IGF2, IL6, and platelet count) were combined and yielded a single model with optimal diagnostic performance. This combination was performed using multivariate discriminate analysis (MDA) for predicting $\mathrm{HCC}$ patients as follows; MDA model $=1.17+$ AFP $(\mathrm{U} / \mathrm{L}) \times 0.002+\mathrm{IGF} 2(\mathrm{pg} /$ $\mathrm{ml}) \times 0.001+\mathrm{IL} 6(\mathrm{pg} / \mathrm{ml}) \times 0.008-$ platelet count $(\times$ $\left.\left.10^{9} / \mathrm{L}\right) \times 0.001\right)$. The median and range of the model were $2.27(1.65-2.9)$ and $1.19(1.14-1.22)$ in $\mathrm{HCC}$ and

Table 2 Diagnostic power of investigated biomarkers and model for differentiating liver cirrhosis vs. HCC

\begin{tabular}{|c|c|c|c|c|c|c|c|}
\hline Markers & AUC $(95 \% \mathrm{Cl})$ & Cut-off & Sensitivity & Specificity & PPV & NPV & Accuracy \\
\hline IGF2 & $0.86(0.78-0.94)$ & 10 & 80 & 73.3 & 80 & 73 & 77 \\
\hline IL6 & $0.82(0.66-0.89)$ & 13.5 & 72 & 70 & 73.5 & 75 & 74.2 \\
\hline AFP & $0.72(0.65-0.8)$ & 400 & 27 & 100 & 100 & 35 & 48 \\
\hline PLT & $0.6(0.51-0.96)$ & 95 & 65 & 52 & 71 & 78 & 60 \\
\hline${ }^{\mathrm{a} M o d e l}$ & $0.97(0.92-1)$ & 1.28 & 90 & 85 & 82 & 92 & 87 \\
\hline
\end{tabular}

${ }^{\mathrm{a}}$ A four-marker model (IGF2 + IL6 + AFP + PLT) 
Table 3 Diagnostic power of AFP to discriminate patients with HCC from patients with cirrhosis in different three staging systems

\begin{tabular}{|c|c|c|c|c|c|c|}
\hline Classification & AUC & Sens $\%$ & Spe\% & PPV\% & NPV\% & $\mathrm{AC} \%$ \\
\hline \multicolumn{7}{|c|}{ Number of nodules ( $n, \%)$} \\
\hline Single $(67,43.2 \%)$ & 0.71 & 22 & 100 & 100 & 53 & 58 \\
\hline Multiple $(88,56.8)$ & 0.74 & 31 & 100 & 100 & 52 & 60 \\
\hline \multicolumn{7}{|c|}{ Macrovascular invasion $(n, \%)$} \\
\hline Absent $(141,91 \%)$ & 0.74 & 25 & 100 & 100 & 38 & 48 \\
\hline Present $(14,9 \%)$ & 0.65 & 50 & 100 & 100 & 90 & 91 \\
\hline \multicolumn{7}{|l|}{ Size of nodules $(n, \%)$} \\
\hline$<2(48,31 \%)$ & 0.72 & 13 & 100 & 100 & 63 & 65 \\
\hline$>2(107,69 \%)$ & 0.75 & 33 & 100 & 100 & 49 & 59 \\
\hline \multicolumn{7}{|l|}{ BCLC stage $(n, \%)$} \\
\hline 0-A $(109,70.3 \%)$ & 0.71 & 19 & 100 & 100 & 41 & 48 \\
\hline B $(46,29.7)$ & 0.8 & 52 & 100 & 100 & 75 & 80 \\
\hline \multicolumn{7}{|l|}{ CLIP stage $(n, \%)$} \\
\hline $0-1(122,79 \%)$ & 0.69 & 17 & 100 & 100 & 39 & 45 \\
\hline $2-3(33,21 \%)$ & 0.88 & 63 & 100 & 100 & 82 & 86 \\
\hline \multicolumn{7}{|l|}{ Okuda stage $(n, \%)$} \\
\hline Stage I $(117,75.5 \%)$ & 0.67 & 23 & 100 & 100 & 41 & 50 \\
\hline Stage II $(38,24.5 \%)$ & 0.89 & 39 & 100 & 100 & 70 & 75 \\
\hline
\end{tabular}

Table 4 Diagnostic power of platelet count to discriminate patients with HCC from patients with cirrhosis in different three staging systems

\begin{tabular}{|c|c|c|c|c|c|c|}
\hline Classification & AUC & Sens\% & Spe\% & PPV\% & NPV\% & $\mathrm{AC} \%$ \\
\hline \multicolumn{7}{|c|}{ Number of nodules $(n, \%)$} \\
\hline Single $(67,43.2 \%)$ & 0.64 & 76 & 52 & 57 & 72 & 63 \\
\hline Multiple $(88,56.8)$ & 0.58 & 57 & 52 & 50 & 58 & 54 \\
\hline \multicolumn{7}{|c|}{ Macrovascular invasion $(n, \%)$} \\
\hline Absent (141, 91\%) & 0.61 & 66 & 52 & 68 & 49 & 60 \\
\hline Present $(14,9 \%)$ & 0.66 & 75 & 52 & 17 & 94 & 54 \\
\hline \multicolumn{7}{|l|}{ Size of nodules $(n, \%)$} \\
\hline$<2(48,31 \%)$ & 0.57 & 62 & 52 & 38 & 74 & 55 \\
\hline$>2(107,69 \%)$ & 0.63 & 66 & 52 & 60 & 59 & 59 \\
\hline \multicolumn{7}{|l|}{ BCLC stage $(n, \%)$} \\
\hline 0-A $(109,70.3 \%)$ & 0.61 & 67 & 52 & 63 & 56 & 60 \\
\hline$B(46,29.7)$ & 0.6 & 62 & 52 & 38 & 74 & 55 \\
\hline \multicolumn{7}{|l|}{ CLIP stage $(n, \%)$} \\
\hline $0-1(122,79 \%)$ & 0.62 & 68 & 52 & 64 & 55 & 61 \\
\hline $2-3(33,21 \%)$ & 0.6 & 60 & 52 & 34 & 76 & 55 \\
\hline \multicolumn{7}{|l|}{ Okuda stage $(n, \%)$} \\
\hline Stage I $(117,75.5 \%)$ & 0.65 & 71 & 52 & 65 & 59 & 63 \\
\hline Stage II $(38,24.5 \%)$ & 0.56 & 55 & 52 & 37 & 69 & 53 \\
\hline
\end{tabular}

Table 5 Diagnostic power of IL6 to discriminate patients with HCC from patients with cirrhosis in different three staging systems

\begin{tabular}{|c|c|c|c|c|c|c|}
\hline Classification & AUC & Sens\% & Spe\% & PPV\% & NPV\% & $\mathrm{AC} \%$ \\
\hline \multicolumn{7}{|c|}{ Number of nodules ( $n, \%)$} \\
\hline Single $(67,43.2 \%)$ & 0.82 & 78 & 70 & 44 & 91 & 72 \\
\hline Multiple $(88,56.8)$ & 0.82 & 78 & 70 & 67 & 81 & 74 \\
\hline \multicolumn{7}{|c|}{ Macrovascular invasion $(n, \%)$} \\
\hline Absent $(141,91 \%)$ & 0.81 & 77 & 70 & 67 & 78 & 73 \\
\hline Present $(14,9 \%)$ & 0.85 & 83 & 70 & 36 & 96 & 72 \\
\hline \multicolumn{7}{|l|}{ Size of nodules ( $n, \%)$} \\
\hline$<2(48,31 \%)$ & 0.82 & 78 & 70 & 44 & 91 & 72 \\
\hline$>2(107,69 \%)$ & 0.82 & 78 & 70 & 67 & 81 & 74 \\
\hline \multicolumn{7}{|l|}{ BCLC stage $(n, \%)$} \\
\hline $0-A(109,70.3 \%)$ & 0.77 & 71 & 70 & 63 & 78 & 71 \\
\hline$B(46,29.7)$ & 0.91 & 91 & 70 & 53 & 96 & 76 \\
\hline \multicolumn{7}{|l|}{ CLIP stage $(n, \%)$} \\
\hline $0-1(122,79 \%)$ & 0.78 & 75 & 70 & 67 & 78 & 72 \\
\hline $2-3(33,21 \%)$ & 0.95 & 88 & 70 & 44 & 96 & 74 \\
\hline \multicolumn{7}{|l|}{ Okuda stage $(n, \%)$} \\
\hline Stage I $(117,75.5 \%)$ & 0.79 & 77 & 70 & 65 & 81 & 73 \\
\hline Stage II $(38,24.5 \%)$ & 0.88 & 80 & 70 & 47 & 85 & 73 \\
\hline
\end{tabular}

Table 6 Diagnostic power of IGF2 to discriminate patients with HCC from patients with cirrhosis in different three staging systems

\begin{tabular}{|c|c|c|c|c|c|c|}
\hline Classification & AUC & Sens $\%$ & Spe\% & PPV\% & NPV\% & $\mathrm{AC} \%$ \\
\hline \multicolumn{7}{|c|}{ Number of nodules $(n, \%)$} \\
\hline Single $(67,43.2 \%)$ & 0.90 & 88 & 73.3 & 67 & 92 & 80 \\
\hline Multiple $(88,56.8)$ & 0.86 & 79 & 73.3 & 73 & 82 & 78 \\
\hline \multicolumn{7}{|c|}{ Macrovascular invasion $(n, \%)$} \\
\hline Absent $(141,91 \%)$ & 0.88 & 83 & 73.3 & 81 & 79 & 80 \\
\hline Present $(14,9 \%)$ & 0.88 & 80 & 73.3 & 36 & 96 & 77 \\
\hline \multicolumn{7}{|l|}{ Size of nodules $(n, \%)$} \\
\hline$<2(48,31 \%)$ & 0.85 & 75 & 73.3 & 56 & 89 & 76 \\
\hline$>2(107,69 \%)$ & 0.89 & 86 & 73.3 & 77 & 85 & 81 \\
\hline \multicolumn{7}{|l|}{ BCLC stage $(n, \%)$} \\
\hline $0-A(109,70.3 \%)$ & 0.88 & 77 & 73.3 & 77 & 79 & 77 \\
\hline$B(46,29.7)$ & 0.88 & 79 & 73.3 & 77 & 88 & 77 \\
\hline \multicolumn{7}{|l|}{ CLIP stage $(n, \%)$} \\
\hline $0-1(122,79 \%)$ & 0.88 & 84 & 73.3 & 77 & 82 & 80 \\
\hline $2-3(33,21 \%)$ & 0.89 & 78 & 73.3 & 77 & 92 & 77 \\
\hline \multicolumn{7}{|l|}{ Okuda stage $(n, \%)$} \\
\hline Stage I $(117,75.5 \%)$ & 0.89 & 87 & 73.3 & 79 & 85 & 82 \\
\hline Stage II $(38,24.5 \%)$ & 0.89 & 79 & 73.3 & 61 & 89 & 77 \\
\hline
\end{tabular}


liver cirrhosis patients, respectively $(p<0.001)$. Using ROC analysis, the model showed an AUC of 0.97, which is higher than that of AFP (0.72), indicating better diagnostic performance. The best cut-off was 1.28 , at which sensitivity and specificity were $90 \%$ and $85 \%$, respectively (Table 2). ROC analysis showed a good performance of the model in patients with single nodule, absent macrovascular invasion, and small tumor size $<2 \mathrm{~cm}$ (AUC of 0.95, 0.94, and 0.95, respectively), compared to AFP (AUC of 0.71, 0.74, and 0.72 , respectively). When applying the three staging systems for HCC classification and then performing ROC analysis, the model achieved perfect performance with AUC of 0.93, 0.94, and 0.95 for BCLC (0-A), CLIP (0-1), and Okuda (stage I), respectively, compared to AFP (AUC of $0.71,0.69$, and 0.67 , respectively) (Table 7).

\section{Discussion}

Various interleukins and growth factors were reported to be generated by hepatoma tissue and secreted in the blood [14, 15]. HCC is an inflammatory-related tumor modulated by JAK/STAT signaling pathway and immune/inflammatory response [16]. JAK/STAT signaling pathway was activated by different cytokines and growth factors such as interferon, interleukin, and IGF, which bind to their respective transmembrane receptors [17]. $\mathrm{HCC}$ is being a biologically heterogeneous tumor, which clarifies the single biomarker performance limitation $[18$, 19]. IL6, as a pro-inflammatory mediator, was reported to prominently increase in hepatic inflammation, viral infection, and HCC [20, 21]. IL6 had specificity and sensitivity of $93 \%$ and $77 \%$ compared with AFP $(41 \%$ and 65\%) [10]. In the current study, IL-6 had a sensitivity and specificity of $78 \%$ and $70 \%$ compared with AFP (27\% and $100 \%$ ) for HCC diagnosis. The liver is the main organ in IGF2 production. According to many studies, IGF2 levels decrease in cirrhosis, compared to normal individuals and increase in HCC [12]. Levels of IGF2 messenger RNA and protein increase $>20$-fold in $15 \%$ of human HCC tissues compared with non-tumor liver tissues [22]. In the current study, the IGF2 level was significantly higher in $\mathrm{HCC}$ patients than in cirrhotic patients. The IGF2 had a sensitivity of $80 \%$, and specificity of $73.3 \%$ in differentiating HCC from cirrhosis. According to Aleem et al., the sensitivity and specificity were $75 \%$ and $60 \%$ [23]. Another study reported a sensitivity and specificity of $73 \%$ and $64 \%$ [24], while a third study found a sensitivity and specificity of $22 \%$ and 91\% [25]. These differences in the results may be due to differences in the inclusion criteria or clinical data of the studied population or different etiology ( $\mathrm{HCV}$ and/or HBV). Thrombocytopenia was present in about twothirds of HCC patients (60.4\%) [26]. In the current study, the platelet count, had an AUC of 0.6, sensitivity of $65 \%$, and specificity of $52 \%$ for diagnosis of HCC. This is in line with Chern-Horng Lee who reported a platelet count AUC of $0.64[27,28]$. The combination of AFP,

Table 7 Performance of the four-marker model (IGF2+ IL6+ AFP+ platelet count) according to the BCLC, CLIP, and Okuda staging systems

\begin{tabular}{|c|c|c|c|c|c|c|}
\hline Classification & AUC $(95 \% \mathrm{Cl})$ & Sens $\%$ & Spe\% & PPV\% & NPV\% & $\mathrm{AC} \%$ \\
\hline \multicolumn{7}{|c|}{ Number of nodules ( $n, \%)$} \\
\hline Single $(67,43.2 \%)$ & $0.95(0.89-1.0)$ & 90 & 85 & 82 & 92 & 87 \\
\hline Multiple $(88,56.8)$ & $0.95(0.88-1.0)$ & 90 & 85 & 82 & 92 & 87 \\
\hline \multicolumn{7}{|c|}{ Macro vascular invasion $(n, \%)$} \\
\hline Absent $(141,91 \%)$ & $0.94(0.86-1.0)$ & 88 & 85 & 88 & 85 & 86 \\
\hline Present $(14,9 \%)$ & $1.0(1.0-1.0)$ & 100 & 85 & 67 & 100 & 88 \\
\hline \multicolumn{7}{|l|}{ Size of nodules $(n, \%)$} \\
\hline$<2(48,31 \%)$ & $0.95(0.87-1.0)$ & 92 & 85 & 85 & 92 & 88 \\
\hline$>2(107,69 \%)$ & $0.98(0.93-1.0)$ & 94 & 85 & 88 & 92 & 99 \\
\hline \multicolumn{7}{|l|}{ BCLC stage $(n, \%)$} \\
\hline 0-A $(109,70.3 \%)$ & $0.93(0.96-1.0)$ & 83 & 85 & 83 & 85 & 84 \\
\hline$B(46,29.7)$ & $0.99(0.96-1.0)$ & 100 & 85 & 80 & 100 & 91 \\
\hline \multicolumn{7}{|l|}{ CLIP stage $(n, \%)$} \\
\hline $0-1(122,79 \%)$ & $0.94(0.85-1.0)$ & 87 & 85 & 87 & 85 & 86 \\
\hline $2-3(33,21 \%)$ & $1.0(1.0-1.0)$ & 100 & 85 & 71 & 100 & 89 \\
\hline \multicolumn{7}{|l|}{ Okuda stage $(n, \%)$} \\
\hline Stage I $(117,75.5 \%)$ & $0.95(0.88-1.0)$ & 92 & 85 & 86 & 92 & 89 \\
\hline Stage II $(38,24.5 \%)$ & $0.96(0.87-1.0)$ & 86 & 85 & 75 & 92 & 85 \\
\hline
\end{tabular}


IGF2, IL6, and platelet count outperformed a single marker in terms of diagnostic performance. AUC increased to 0.97 , with $90 \%$ sensitivity and $85 \%$ specificity. Furthermore, this model showed an excellent performance in patients with a single nodule (0.95 AUC and $90 \%$ sensitivity) and tumor size $<2 \mathrm{~cm}(0.95$ AUC and 92\% sensitivity). In contrast, alpha-fetoprotein routine test (HCC-ART) and simplified HCC-ART score had sensitivities of $70 \%$ and $82 \%$, respectively, in diagnosing small-size HCC [29]. The combination of AFP and Desgamma-carboxyprothrombin yields an AUC of 0.846 [30]. Omran et al. reported that the combination of acid glycoprotein, albumin, $\mathrm{C}$ reactive protein, and AFP has an AUC of 0.92 and a sensitivity of $85 \%$ [31]. According to Attallah et al., combining cytokeratin-1 and nuclear protein-52 with AFP provides an AUC, sensitivity, and specificity of $0.90,80 \%$, and $92 \%$, respectively, for identifying HCC [32]. The combination of osteopontin (OPN) and AFP increases the AUC to 0.88. Also, the combination of OPN and liver enzymes increases the AUC to 0.87 [33]. In contrast, the combination of AFP and ultrasound has a low sensitivity of $63 \%$ for early HCC diagnosis. Furthermore, the sensitivities of $\mathrm{CT}$ and MRI in predicting early $\mathrm{HCC}$ are $62.5 \%$ and $83.7 \%$, respectively [5].

\section{Conclusion}

The current study provided a four-marker model (IGF2, IL6, PLT, and AFP) that could improve the early diagnosis of HCC.

\section{Abbreviations \\ AC: Accuracy; AFP: Alpha-fetoprotein; HCC-ART: Alpha-fetoprotein routine test; AUC: Area under ROC curve; AASLD: Association for the Study of Liver Diseases; BCLC: Barcelona Clinic Liver Cancer; CLIP: Cancer of Liver Italian Program; CT: Computed tomography; HCC: Hepatocellular carcinoma; IGF 2: Insulin-like growth factor 2; IL-6: Interleukin; MRI: Magnetic resonance image; MDA: Multivariate discriminate analysis; NPV: Negative predictive value; OPN: Osteopontin; PPV: Positive predictive value; SD: Standard deviation; Sen: Sensitivity; Spe: Specificity; SPSS: Statistical package for social science}

\section{Acknowledgements}

Not applicable.

\section{Authors' contributions}

OM, FK and EF conceived and designed experiments. OM, ET and MS contributed to the analysis and/or interpretation of data. OM, FK and MS drafted the manuscript. OM, FK, and ET revised it critically for important intellectual content. All authors have read the manuscript and approved the submission.

\section{Funding}

This research did not receive any specific grant from funding agencies in the public, commercial, or not-for-profit sectors.

\section{Availability of data and materials}

Authors declare that all generated and analyzed data are included in the article.

\section{Declarations}

\section{Ethics approval and consent to participate}

The study was approved by the Ethics Committee of Faculty of Medicine, AlAzhar University, New Damietta (Code \# IRB 00012367-18-10-002). A novel model based on interleukin 6 and insulin-like growth factor II for detection of hepatocellular carcinoma associated with hepatitis C virus. Informed written consent was signed by all patients in compliance with the ethical guidelines of the 1975 Helsinki Declaration.

\section{Consent for publication}

Not applicable

\section{Competing interests}

The authors declare that they have no competing interests.

\section{Author details}

${ }^{1}$ Chemistry Department, Faculty of Science, Helwan University, Ain Helwan, Cairo 11795, Egypt. ${ }^{2}$ Chemistry Department, Faculty of Science, Damietta University, New Damietta, Damietta, Egypt. ${ }^{3}$ Clinical Pathology Department, Faculty of Medicine, Al-Azhar University, New Damietta, Egypt. ${ }^{4}$ Tropical Medicine Department, Faculty of Medicine, Mansoura University, Mansoura, Egypt

Received: 7 April 2021 Accepted: 2 October 2021

Published online: 29 October 2021

\section{References}

1. Ahn JC, Teng PC, Chen PJ, Posadas E, Tseng HR, Lu SC, Yang JD (2020) Detection of circulating tumor cells and their implications as a novel biomarker for diagnosis, prognostication, and therapeutic monitoring in hepatocellular carcinoma. Hepatol 73(1):422-436. https://doi.org/10.1002/ hep.31165

2. Parikh ND, Mehta AS, Singal AG, Block T, Marrero JA, Lok AS (2020) Biomarkers for the early detection of hepatocellular carcinoma. Cancer Epidemiol Biomarkers Prev 29(12):2495-2503. https://doi.org/10.1158/10559965.EPI-20-0005

3. Rashed WM, Kandeil MA, Mahmoud MO, Ezzat S (2020) Hepatocellular carcinoma (HCC) in Egypt: a comprehensive overview. J Egypt Natl Canc Inst 32(1):1-11. https://doi.org/10.1186/s43046-020-0016-x

4. Ayuso C, Rimola J, Vilana R, Burrel M, Darnell A, García-Criado Á, Bianchi L, Belmonte E, Caparroz C, Barrufet M, Bruix J, Brú C (2018) Diagnosis and staging of hepatocellular carcinoma (HCC): current guidelines. Eur J Radiol 101:72-81. https://doi.org/10.1016/j.ejrad.2018.01.025

5. Tzartzeva K, Obi J, Rich NE, Parikh ND, Marrero JA et al (2018) Surveillance imaging and alpha fetoprotein for early detection of hepatocellular carcinoma in patients with cirrhosis: a meta-analysis. Gastroenterology 154 : 1706-1718. e1701

6. Balaceanu LA (2019) Biomarkers vs imaging in the early detection of hepatocellular carcinoma and prognosis. World J Clin Cases 7(12):13671382. https://doi.org/10.12998/wjcc.v7.i12.1367

7. Shiraha $\mathrm{H}$, Iwamuro $\mathrm{M}$, Okada $\mathrm{H}$ (2020) Hepatic stellate cells in liver tumor. Adv Exp Med Biol 1234:43-56. https://doi.org/10.1007/978-3-030-37184-5_4

8. Pavlovic N, Rani B, Gerwins P, Heindryckx F (2019) Platelets as key factors in hepatocellular carcinoma. Cancers 11(7):1022. https://doi.org/10.3390/ca ncers 11071022

9. Uciechowski P, Dempke WC (2020) Interleukin-6: a Masterplayer in the cytokine network. Oncology 98(3):131-137. https://doi.org/10.1159/ 000505099

10. Shakiba E, Ramezani M, Sadeghi M (2018) Evaluation of serum interleukin-6 levels in hepatocellular carcinoma patients: a systematic review and metaanalysis. Clin Exp Hepatol 4(3):182-190. https://doi.org/10.5114/ceh.2018. 78122

11. Yang H, Xuefeng $Y$, Jianhua $X$ (2020) Systematic review of the roles of interleukins in hepatocellular carcinoma. Clinica Chimica Acta 506:33-43. https://doi.org/10.1016/j.cca.2020.03.001

12. Adamek A, Kasprzak A (2018) Insulin-like growth factor (IGF) system in liver diseases. Int J Mol Sci 19(5):1308. https://doi.org/10.3390/ijms19051308

13. Chung H, Kudo M, Takahashi S, Hagiwara S, Sakaguchi Y, Inoue T, Minami Y, Ueshima K, Fukunaga T, Matsunaga T (2008) Comparison of three current staging systems for hepatocellular carcinoma: Japan integrated staging 
score, new Barcelona Clinic Liver Cancer staging classification, and Tokyo score. J Gastroenterol Hepatol 23(3):445-452. https://doi.org/10.1111/j.144 0-1746.2007.05075.x

14. Chiba T, Suzuki E, Saito T, Ogasawara S, Ooka Y, Tawada A, Iwama A, Yokosuka O (2015) Biological features and biomarkers in hepatocellular carcinoma. World J Hepatol 7(16):2020-2028. https://doi.org/10.4254/wjh.v7. i16.2020

15. Alqahtani A, Khan Z, Alloghbi A, S Said Ahmed T, Ashraf M, et al. (2019) Hepatocellular carcinoma: molecular mechanisms and targeted therapies. Medicina 55(9):526. https://doi.org/10.3390/medicina55090526

16. Hin Tang JJ, Hao Thng DK, Lim JJ, Toh TB (2020) JAKJSTAT signaling in hepatocellular carcinoma. Hepat Oncol 7(1):HEP18. https://doi.org/10.2217/ hep-2020-0001

17. Refolo MG, Messa C, Guerra V, Carr BI, D'Alessandro R (2020) Inflammatory mechanisms of HCC development. Cancers 12(3):641. https://doi.org/10.33 90/cancers 12030641

18. Lou J, Zhang L, Lv S, Zhang C, Jiang S (2017) Biomarkers for hepatocellular carcinoma. Biomark Cancer 9:1-9. https://doi.org/10.1177/1179299X16684640

19. Ozgor D, Otan E (2020) HCC and tumor biomarkers: does one size fits all? J Gastrointest Cancer 51(4):1122-1126. https://doi.org/10.1007/s1202 9-020-00485-x

20. Lokau J, Schoeder V, Haybaeck J, Garbers C (2019) Jak-Stat signaling induced by interleukin-6 family cytokines in hepatocellular carcinoma. Cancers 11(11):1704. https://doi.org/10.3390/cancers11111704

21. Adnan F, Khan NU, lqbal A, Ali I, Petruzziello A, Sabatino R, Guzzo A Loquercio G, Botti G, Khan S, Naeem M, Khan MI (2020) Interleukin-6 polymorphisms in HCC patients chronically infected with HCV. Infect Agent Cancer 15(1):1-7. https://doi.org/10.1186/s13027-020-00285-9

22. Martinez-Quetglas I, Pinyol R, Dauch D, Torrecilla S, Tovar V, Moeini A, Alsinet C, Portela A, Rodriguez-Carunchio L, Solé M, Lujambio A, Villanueva A, Thung S, Esteller M, Zender L, Llovet JM (2016) IGF2 is up-regulated by epigenetic mechanisms in hepatocellular carcinomas and is an actionable oncogene product in experimental models. Gastroenterology 151(6):11921205. https://doi.org/10.1053/j.gastro.2016.09.001

23. Aleem E, Elshayeb A, Elhabachi N, Mansour AR, Gowily A et al (2012) Serum IGFBP-3 is a more effective predictor than IGF-1 and IGF-2 for the development of hepatocellular carcinoma in patients with chronic HCV infection. Oncol Lett 3(3):704-712. https://doi.org/10.3892/ol.2011.546

24. Rehem RN, El-Shikh WM (2011) Serum IGF-1, IGF-2 and IGFBP-3 as parameters in the assessment of liver dysfunction in patients with hepatic cirrhosis and in the diagnosis of hepatocellular carcinoma. Hepatogastroenterology 58:949-954

25. Morace C, Cucunato M, Bellerone R, De Caro G, Crinò S et al (2012) Insulinlike growth factor-II is a useful marker to detect hepatocellular carcinoma? Eur J Intern Med 23(6):e157-e161. https://doi.org/10.1016/j.ejim.2012.04.014

26. Scheiner B, Kirstein M, Popp S, Hucke F, Bota S, Rohr-Udilova N, Reiberger T, Müller C, Trauner M, Peck-Radosavljevic M, Vogel A, Sieghart W, Pinter M (2019) Association of platelet count and mean platelet volume with overall survival in patients with cirrhosis and unresectable hepatocellular carcinoma. Liver Cancer 8(3):203-217. https://doi.org/10.1159/000489833

27. Lee CH, Lin YJ, Lin CC, Yen CL, Shen CH, Chang CJ, Hsieh SY (2015) Pretreatment platelet count early predicts extrahepatic metastasis of human hepatoma. Liver Int 35(10):2327-2336. https://doi.org/10.1111/liv.12817

28. Kubo S, Tanaka H, Shuto T, Takemura S, Yamamoto T, Uenishi T, Tanaka S, Ogawa M, Sakabe K, Yamazaki K, Hirohashi K (2004) Correlation between low platelet count and multicentricity of hepatocellular carcinoma in patients with chronic hepatitis C. Hepatol Res 30(4):221-225. https://doi. org/10.1016/j.hepres.2004.10.005

29. Attallah AM, Omran MM, Attallah AA, Abdelrazek MA, Farid K, el-Dosoky I (2017) Simplified HCC-ART score for highly sensitive detection of small-sized and early-stage hepatocellular carcinoma in the widely used Okuda, CLIP, and BCLC staging systems. Int J Clin Oncol 22(2):332-339. https://doi.org/1 0.1007/s10147-016-1066-x

30. Yu R, Ding S, Tan W, Tan S, Tan Z et al (2015) Performance of protein induced by vitamin $k$ absence or antagonist-II (PIVKA-II) for hepatocellular carcinoma screening in Chinese population. Hepat Mon 15:e28806

31. Omran MM, Emran TM, Farid K, Eltaweel FM, Omar MA, Bazeed FB (2016) An easy and useful noninvasive score based on a-1-acid glycoprotein and Creactive protein for diagnosis of patients with hepatocellular carcinoma associated with hepatitis C virus infection. J Immunoassay Immunochem 37(3):273-288. https://doi.org/10.1080/15321819.2015.1132229
32. Attallah AM, El-Far M, Malak CAA, Omran MM, Shiha GE et al (2015) HCCDETECT: a combination of nuclear, cytoplasmic, and oncofetal proteins as biomarkers for hepatocellular carcinoma. Tumor Biol 36(10):7667-7674. https://doi.org/10.1007/s13277-015-3501-4

33. Duarte-Salles T, Misra S, Stepien M, Plymoth A, Muller D, Overvad K, Olsen A, Tjønneland A, Baglietto L, Severi G, Boutron-Ruault MC, Turzanski-Fortner R, Kaaks R, Boeing H, Aleksandrova K, Trichopoulou A, Lagiou P, Bamia C, Pala V, Palli D, Mattiello A, Tumino R, Naccarati A, Bueno-de-Mesquita HB(), Peeters PH, Weiderpass E, Quirós JR, Agudo A, Sánchez-Cantalejo E, Ardanaz E, Gavrila D, Dorronsoro M, Werner M, Hemmingsson O, Ohlsson B, Sjöberg K, Wareham NJ, Khaw KT, Bradbury KE, Gunter MJ, Cross AJ, Riboli E, Jenab M, Hainaut P, Beretta L (2016) Circulating osteopontin and prediction of hepatocellular carcinoma development in a large European population. Cancer Prev Res 9(9):758-765. https://doi.org/10.1158/1940-6207.CAPR-150434

\section{Publisher's Note}

Springer Nature remains neutral with regard to jurisdictional claims in published maps and institutional affiliations.

\section{Submit your manuscript to a SpringerOpen ${ }^{\circ}$ journal and benefit from:}

- Convenient online submission

- Rigorous peer review

- Open access: articles freely available online

- High visibility within the field

- Retaining the copyright to your article

Submit your next manuscript at $>$ springeropen.com 